\title{
Sex-related associations between body height and cognitive impairment among low-income elderly adults in rural China: a population-based cross-sectional study
}

Dongwang $\mathrm{Qi}^{1 \dagger}$, Chanhong Shi ${ }^{1 \dagger}$, Rongyan Mao ${ }^{1 \dagger}$, Xuewei Yang ${ }^{1}$, Jinhui Song ${ }^{1}$, Yanjia Wang ${ }^{2}$, Jun Tu ${ }^{3,4,5}$, Jinghua Wang ${ }^{3,4,5^{*}}$, Xianjia Ning ${ }^{3,4,5^{*}}$ and Yi Wu ${ }^{1^{*}}$ (D)

\begin{abstract}
Background: Body height is a marker of childhood health and cumulative net nutrition during growth periods. However, sex-specific associations between body height and cognitive impairment are not well known in northern rural China.

Methods: We assessed sex differences in the association between body height and cognitive impairment in a lowincome elderly population in rural China. A population-based cross-sectional study was conducted from April 2014 to August 2014 to collect basic information from elderly residents aged 60 years and older in rural areas of Tianjin, China. Body height and Mini Mental State Examination (MMSE) scores were measured, and the relationships between these variables were assessed.
\end{abstract}

Results: A total of 1081 residents with a mean age of 67.7 years were enrolled in this study. After adjusting for age, educational attainment, smoking status, drinking status, and the presence of hypertension, diabetes, and hypercholesterolemia, higher body height was found to be associated with a decreased prevalence of cognitive impairment in elderly men. Each 1-dm increase in height was associated with a 37\% decrease in the prevalence of cognitive impairment. However, there was no significant association between body height and cognitive impairment among elderly women.

Conclusion: In conclusion, shorter body height was related to cognitive impairment independently of age, educational attainment, lifestyle factors, and health-related comorbid factors among low-income elderly men in rural China. Accordingly, shorter elderly men may be targeted for effective dementia prevention in rural China.

Keywords: Cognitive impairment, Body height, Sex difference, Epidemiology, Population-based study

*Correspondence: jwang3@tmu.edu.cn; xning@tmu.edu.cn; snwuyi@163. com

${ }^{\dagger}$ Dongwang Qi, Chanhong Shi and Rongyan Mao have equal contribution to this work

${ }^{1}$ Department of Neurology, Yiwu Central Hospital \& The Affiliated

Yiwu Hospital of Wenzhou Medical College, 699 Jiangdong Road, Yiwu City 322000, Zhejiang, China

${ }^{3}$ Department of Neurology, Tianjin Medical University General Hospital, 154 Anshan Road, Heping District, Tianjin 300052, China

Full list of author information is available at the end of the article

\section{Background}

Cognitive disorders, including dementia and mild cognitive impairment, are leading causes of disability and global public health priorities in aging populations [1, 2]. According to the World Alzheimer Report 2016, there were approximately 47 million patients with dementia worldwide, and this number is estimated to increase to more than 131 million by 2050 . The total 
costs of dementia worldwide were approximately 604 billion US dollars in 2010 [3]. At present, most people with dementia live in developing countries, and this proportion is expected to increase to $71.2 \%$ by 2040 [4]. Moreover, the number of people living with dementia in China was approximately 10 to 12 million in 2014, which is the largest population worldwide and accounts for $25 \%$ of the total dementia population [5]. In China, the total costs of dementia were estimated to be 248.71 billion US dollars in 2020, posing a huge economic and social burden [5].

Although body height is affected by genetics and the environment, it is a measure of childhood health and cumulative net nutrition during growth periods [6]. Childhood height and leg length are predictors of intelligence and cognitive function in early life [7]. Most studies have reported positive relationships between body height and cognitive performance among elderly men in Western countries [8-12]. However, in Asia, only a few studies have been conducted in southern China and Korea, and the reported relationships between height and cognitive function are controversial. A cross-sectional study from the Guangzhou Biobank Cohort suggested that body height was positively associated with cognitive function, but only in older men and younger women [13]. Another community-based study indicated that shorter sitting height and longer leg length, rather than shorter body height, were associated with dementia among elderly women in urban Shanghai [14].

However, the relationships between body height in late life and cognitive impairment in low-income populations in northern rural China remain uncertain. In particular, sex-related associations between body height and cognitive impairment are not well known in northern rural China.

Therefore, the aim of this study was to evaluate the sexrelated associations between body height and cognitive impairment among low-income elderly adults in northern rural China.

\section{Methods}

\section{Study population}

This was a population-based, cross-sectional study conducted from April 2014 to August 2014 in rural areas of Tianjin, China. The participants were from the Tianjin Brain Study, which has been described previously [15, 16]. All residents aged 60 years and older without vision and auditory dysfunction were invited to participate in this study. However, individuals with a history of myocardial infarction, stroke, congenital hypophrenia, and/or mental illness were excluded from the study.

\section{Risk factors and physical examinations}

This study was conducted through face-to-face interviews by trained research staff. A pre-designed questionnaire was used to collect the following information: demographic information (including name, sex, date of birth, and education level), individual medical history (including the presence of hypertension and diabetes mellitus), and lifestyle factors (including smoking and drinking). A physical examination was performed to obtain information on body height, weight, and waist circumference (WC) with participants wearing thin clothes. Body height was measured in decimeters. Blood pressure (BP) measurements were performed using an electronic sphygmomanometer. Subjects were asked to remain resting in a sitting position for $15 \mathrm{~min}$ before testing; BP was measured three times and the mean was obtained. The levels of fasting blood glucose (FBG), total cholesterol (TC), triglycerides (TG), high-density lipoprotein cholesterol (HDL-C), and low-density lipoprotein cholesterol (LDL-C) were analyzed in the central laboratory of Tianjin Ji County People's Hospital. Furthermore, cognitive function was measured using the Mini Mental State Examination (MMSE) owing to its high sensitivity and specificity in screening for cognitive impairment [17].

\section{Cognitive impairment criteria}

The diagnostic criterion of cognitive impairment was based on MMSE score according to the participant's education level. Cognitive impairment was defined by an MMSE score $<17$ points in the group with no formal education (the illiterate group), $<22$ points in the group with a primary school education, and $<26$ points in the group with a junior school education and above [18].

\section{Definitions}

Hypertension was defined by systolic blood pressure $(\mathrm{SBP}) \geq 140 \mathrm{mmHg}$, diastolic blood pressure $(\mathrm{DBP}) \geq 90 \mathrm{mmHg}$, the use of antihypertensive drugs, or a history of hypertension. Diabetes was defined as an FBG value $\geq 7.0 \mathrm{mmol} / \mathrm{L}$, taking medication for diabetes, or a self-reported history of diabetes. Hypercholesterolemia was defined as a total cholesterol value $>5.72 \mathrm{mmol} / \mathrm{L}$ or taking lipid-lowering drugs. Smoking was defined as smoking $\geq 1$ cigarette daily for more than 1 year. Drinking was defined as drinking $>50 \mathrm{~mL}$ of alcohol at least once per week for more than 6 months.

\section{Statistical analysis}

Continuous variables are described as means and standard deviations; the Student's $t$ test was used to compare differences between two groups. Categorical variables are presented as numbers with frequencies, and the 
chi-squared test was performed to compare differences between two groups. The participants were categorized into three age groups $(60-64,65-69$, and $\geq 70$ years) and three education groups according to the length of formal education $(0-5,6-8$, and $\geq 9$ years). Multiple logistic regression analyses were used to evaluate the relationship between body height and cognitive impairment. The independent variables were selected as those found to be statistically significant in the univariate analyses. The relationship between body height and cognitive impairment was presented as adjusted odds ratios (ORs) and 95\% confidence intervals (CIs) after adjusting for covariates. Three logistic regression analysis models were developed to examine the association between body height and cognitive impairment. Model 1 adjusted for age and educational attainment (categorical variables). Model 2 was based on model 1, with additional adjustment for lifestyle factors (smoking and drinking). Model 3 was based on model 2, with additional adjustments for hypertension, diabetes, and hypercholesterolemia.

All statistical analyses were performed with SPSS version 19.0 statistical software (SPSS Inc., Chicago, IL), and a two-sided $P \leq 0.05$ was considered statistically significant.

\section{Results}

\section{Demographic characteristics}

A total of 1081 residents aged more than 60 years were enrolled in this study. There were 500 men $(46.3 \%)$ and 581 women $(53.7 \%)$, with mean age of 67.7 years overall, 68.0 years for men, and 67.5 years for women. In this rural population, the prevalence of cognitive impairment was $33.2 \%$ (26.6\% in men and $38.9 \%$ in women). Moreover, the mean height was $15.9 \mathrm{dm}(\mathrm{dm} ; 16.5 \mathrm{dm}$ for men and $15.3 \mathrm{dm}$ for women). In this population, women were more likely to have lower educational attainment and MMSE scores and higher DBP, FBG, TC, TG, HDL-C, and LDL-C levels $(P<0.05)$ (Table 1$)$.

\section{Associations between cognitive impairment and risk factors by sex in the univariate analysis}

Cognitive impairment was related to older age, lower educational attainment, and higher SBP in both men and women. Moreover, height and WC were associated with cognitive impairment in men (Table 2).

\section{Associations between height and cognitive impairment by sex and age in the multivariate analysis}

Body height was associated with cognitive impairment among elderly men; each 1-dm increase in body height was associated with a $33 \%$ decrease (95\% CI $0.45-0.99$; $P=0.050)$ in the prevalence of cognitive impairment after adjusting for age, education group, WC, and SBP.
In a subgroup analysis, the association remained consistent among adults aged 60-64 years. Each 1-dm increase in body height was associated with a $65 \%$ decrease $(95 \%$ CI $0.17-0.74 ; P=0.006)$ in the prevalence of cognitive impairment in elderly men aged 60-64 years.

Body height was related to the prevalence of cognitive impairment in models 1, 2, and 3 for elderly men. Each $1-\mathrm{dm}$ increase in body height was associated with a $37 \%$ decrease (95\% CI 0.43-0.94; $P=0.022)$ in the prevalence of cognitive decline after adjusting for age, education, smoking, drinking, hypertension, diabetes, and hypercholesterolemia in model 3. Each 1-dm increase in body height was associated with a $67 \%$ decrease $(95 \%$ CI $0.16-$ $0.69 ; P=0.003)$ in the prevalence of cognitive decline for elderly men aged 60-64 years in model 3 . However, there was no significant association between body height and cognitive impairment among elderly women (Table 3 ).

\section{Discussion}

In the present population-based study, we evaluated the sex-related associations between body height and cognitive impairment among low-income elderly adults in rural China. We found that shorter body height was related to cognitive impairment independently of age, educational attainment, lifestyle factors, and health-related comorbid factors for elderly men, but not for elderly women. In a subgroup analysis, the association remained consistent among elderly men aged 60-64 years; each 1 -dm increase in body height was associated with a $65 \%$ decrease in the prevalence of cognitive impairment.

Cardiovascular risk factors, including hypertension, diabetes mellitus, hyperlipidemia, and smoking, have been linked with cognitive decline in adults Childhood is a critical period for both brain and body development. Anthropometric measures, including head circumference and body height, are key indicators for brain and body development. A smaller head circumference was reported to be associated with poorer global cognitive performance and cognitive reserve $[19,20]$. The Honolulu-Asia Aging Study suggested that height in middle life was a marker of childhood growth and was associated with dementia and cognitive impairment among elderly Japanese-American men living in Hawaii [7]. In a large Belarusian prospective birth cohort study, a taller height between birth and age 6.5 years was associated with higher cognitive scores at age 16 years, with a 2.5 point $(95 \%$ CI $1.9,3.0)$ per standard deviation increase [21]. Most studies in Western countries have suggested that height is associated with cognitive function in older age. A European study involving 11 countries reported that height was positively and significantly correlated with cognitive performance in later life, with each $10-\mathrm{cm}$ increase in body height associated with a 0.04-standard 
Table 1 Demographic characteristics and risk factors for all participants by sex group

\begin{tabular}{|c|c|c|c|c|}
\hline Risk factors & Men & Women & Total & $P$ \\
\hline Total, $n(\%)$ & $500(46.3)$ & $581(53.7)$ & $1081(100)$ & - \\
\hline Age, means (SD) & $67.96(6.42)$ & $67.47(6.48)$ & $67.70(6.46)$ & 0.209 \\
\hline Age group, $n(\%)$ & & & & 0.209 \\
\hline 60-64 years & $190(38.0)$ & $249(42.9)$ & $439(40.6)$ & \\
\hline $65-69$ years & $138(27.6)$ & $157(27.0)$ & $295(27.3)$ & \\
\hline$\geq 70$ years & $172(34.4)$ & $175(30.1)$ & $348(32.1)$ & \\
\hline Education, years, mean (SD) & $5.35(2.72)$ & $2.62(2.94)$ & $3.88(3.15)$ & $<0.001$ \\
\hline Education, $n(\%)$ & & & & $<0.001$ \\
\hline $0-5$ years & $203(40.6)$ & $451(77.6)$ & $654(60.5)$ & \\
\hline $6-8$ years & $219(43.8)$ & $101(17.4)$ & $320(29.6)$ & \\
\hline$\geq 9$ years & $78(15.6)$ & $29(5.0)$ & $107(9.9)$ & \\
\hline Smoking, $n$ (\%) & & & & $<0.001$ \\
\hline No & $136(27.2)$ & $261(44.9)$ & $397(36.7)$ & \\
\hline Yes & $364(72.8)$ & $320(55.1)$ & $684(63.3)$ & \\
\hline Drinking, $n(\%)$ & & & & $<0.001$ \\
\hline No & $280(56.0)$ & $492(84.7)$ & $772(71.4)$ & \\
\hline Yes & $220(44.0)$ & $89(15.3)$ & 309 (28.6) & \\
\hline Hypertension, n (\%) & & & & 0.568 \\
\hline No & $106(21.2)$ & $115(19.8)$ & $221(20.4)$ & \\
\hline Yes & $394(78.8)$ & $466(80.2)$ & $860(79.6)$ & \\
\hline Diabetes, $n(\%)$ & & & & 0.012 \\
\hline No & $432(86.4)$ & $469(80.7)$ & $901(83.3)$ & \\
\hline Yes & $68(13.6)$ & $112(19.3)$ & $180(16.7)$ & \\
\hline MMSE score, mean (SD) & $22.30(4.54)$ & $19.13(5.31)$ & $20.60(5.21)$ & $<0.001$ \\
\hline MMSE group, $n(\%)$ & & & & $<0.001$ \\
\hline Non-Cl & $367(73.4)$ & $355(61.1)$ & $722(66.8)$ & \\
\hline $\mathrm{Cl}$ & $133(26.6)$ & $226(38.9)$ & $359(33.2)$ & \\
\hline Body height (dm), mean (SD) & $16.46(0.56)$ & $15.32(0.55)$ & $15.85(0.80)$ & $<0.001$ \\
\hline WC $(\mathrm{cm})$, mean $(\mathrm{SD})$ & $88.58(9.29)$ & $89.21(8.68)$ & $88.92(8.97)$ & 0.250 \\
\hline SBP, mean (SD) & $153.66(23.06)$ & $154.95(23.28)$ & $154.35(23.18)$ & 0.360 \\
\hline DBP, mean (SD) & $87.05(11.53)$ & $85.52(11.76)$ & $86.23(11.67)$ & 0.031 \\
\hline FBG, mean (SD) & $5.84(1.18)$ & $6.18(1.93)$ & $6.02(1.64)$ & 0.001 \\
\hline $\mathrm{TC}$, mean $(\mathrm{SD})$ & $4.56(0.95)$ & $5.18(1.07)$ & $4.89(1.06)$ & $<0.001$ \\
\hline TG, mean (SD) & $1.41(0.83)$ & $1.82(1.29)$ & $1.63(1.12)$ & $<0.001$ \\
\hline $\mathrm{HDL}$, mean (SD) & $1.42(0.44)$ & $1.53(0.47)$ & $1.48(0.46)$ & $<0.001$ \\
\hline LDL, mean (SD) & $2.49(0.79)$ & $2.85(0.90)$ & $2.68(0.87)$ & $<0.001$ \\
\hline
\end{tabular}

$S D$ standard deviation; MMSE Mini-Mental state examination; $C l$ cognitive impairment; $W C$ waist circumstance; $S B P$ systolic blood pressure; $D B P$ diastolic blood pressure; $F B G$ fasting blood glucose; $T C$ total cholesterol; $T G$ triglycerides; $H D L$ high-density lipoprotein cholesterol; $L D L$ low-density lipoprotein cholesterol

deviation increase in a global cognitive score [8]. A cross-sectional study in a Portuguese community found that height was a good independent predictor of general cognitive function in later life, especially with respect to executive function and memory [9].

However, the relationships between body height in later life and cognitive impairment remain controversial in Asian countries. The Hallym Aging Study in Korea found sex-related associations between height and cognitive function. Among community-dwelling elderly men, compared with the tallest group, the shortest group had a 3.2-fold higher risk of cognitive impairment (OR 4.20; 95\% CI 1.02-17.36), but this association was not present among elderly women [22]. A cross-sectional study from the Guangzhou Biobank Cohort suggested that body height was positively associated with cognitive function, but only in older men and younger women [13]. In addition, shorter sitting height and lower relative sitting height were found to be significantly associated with dementia among elderly women in the urban Shanghai 
Table 2 Association of cognitive impairment with demographic characteristics and risk factors by sex in univariate analysis

\begin{tabular}{|c|c|c|c|c|c|c|}
\hline \multirow[t]{2}{*}{ Characteristics } & \multicolumn{3}{|l|}{ Male } & \multicolumn{3}{|l|}{ Female } \\
\hline & Non-Cl & $\mathrm{Cl}$ & $\mathbf{P}$ & Non-Cl & $\mathrm{Cl}$ & $\mathbf{P}$ \\
\hline Age, means (SD) & $66.89(5.71)$ & $70.92(7.31)$ & $<0.001$ & $66.04(5.36)$ & $69.71(7.41)$ & $<0.001$ \\
\hline Age group, $n(\%)$ & & & $<0.001$ & & & $<0.001$ \\
\hline 60-64 years & $158(83.2)$ & $32(16.8)$ & & $175(70.3)$ & $74(29.7)$ & \\
\hline $65-69$ years & $107(77.5)$ & $31(22.5)$ & & $105(66.9)$ & $52(33.1)$ & \\
\hline$\geq 70$ years & $102(59.3)$ & $70(40.7)$ & & $75(42.9)$ & $100(57.1)$ & \\
\hline Education, years, mean (SD) & $5.64(2.57)$ & $4.55(2.97)$ & $<0.001$ & $3.43(2.99)$ & $1.34(2.36)$ & $<0.001$ \\
\hline Education, $n(\%)$ & & & $<0.001$ & & & $<0.001$ \\
\hline 0-5 years & $128(63.1)$ & 75 (36.9) & & $247(54.8)$ & $204(45.2)$ & \\
\hline $6-8$ years & $180(82.2)$ & $39(17.8)$ & & $84(83.2)$ & $17(16.8)$ & \\
\hline$\geq 9$ years & $59(75.6)$ & $19(24.4)$ & & $24(82.8)$ & $65(17.2)$ & \\
\hline Smoking, $n(\%)$ & & & 0.121 & & & 0.672 \\
\hline No & $93(68.4)$ & $274(31.6)$ & & $157(60.2)$ & $104(39.8)$ & \\
\hline Yes & $274(75.3)$ & $90(24.7)$ & & $198(61.9)$ & $122(38.1)$ & \\
\hline Drinking, $n(\%)$ & & & 0.922 & & & 0.536 \\
\hline No & $206(73.6)$ & $74(26.4)$ & & $298(60.6)$ & $194(39.4)$ & \\
\hline Yes & $161(73.2)$ & $59(26.8)$ & & $57(64.0)$ & $32(36.0)$ & \\
\hline Hypertension, n (\%) & & & 0.125 & & & 0.221 \\
\hline No & $84(79.2)$ & $22(20.8)$ & & $76(66.1)$ & $39(33.9)$ & \\
\hline Yes & $283(71.8)$ & $111(28.2)$ & & $279(59.9)$ & $187(40.1)$ & \\
\hline Diabetes, $n(\%)$ & & & 0.081 & & & 0.325 \\
\hline No & $323(74.0)$ & $109(26.0)$ & & $282(60.1)$ & $187(39.9)$ & \\
\hline Yes & $44(74.8)$ & $24(25.2)$ & & $73(65.2)$ & $39(34.8)$ & \\
\hline Body height (dm), mean (SD) & $16.51(0.55)$ & $16.31(0.56)$ & $<0.001$ & $15.35(0.56)$ & $15.29(0.55)$ & 0.191 \\
\hline WC $(\mathrm{cm})$, mean $(\mathrm{SD})$ & $89.14(9.26)$ & $87.04(9.25)$ & 0.025 & $89.96(9.00)$ & $89.61(8.15)$ & 0.379 \\
\hline SBP, mean (SD) & $152.27(22.40)$ & $157.49(24.47)$ & 0.025 & $152.95(22.13)$ & $158.10(24.71)$ & 0.009 \\
\hline DBP, mean (SD) & $87.14(10.91)$ & $86.80(13.12)$ & 0.790 & $85.38(11.41)$ & $85.73(12.31)$ & 0.729 \\
\hline FBG, mean (SD) & $5.79(1.15)$ & $6.01(1.26)$ & 0.064 & $6.23(2.05)$ & $6.11(1.74)$ & 0.467 \\
\hline TC, mean (SD) & $4.55(0.97)$ & $4.57(0.92)$ & 0.812 & $5.15(1.06)$ & $5.20(1.06)$ & 0.400 \\
\hline TG, mean (SD) & $1.42(0.83)$ & $1.41(0.85)$ & 0.790 & $1.86(1.45)$ & $1.75(0.97)$ & 0.346 \\
\hline HDL, mean (SD) & $1.41(0.42)$ & $1.44(0.49)$ & 0.535 & $1.51(0.44)$ & $1.56(0.50)$ & 0.184 \\
\hline LDL, mean (SD) & $2.49(0.82)$ & $2.48(0.73)$ & 0.883 & $2.84(0.91)$ & $2.87(0.90)$ & 0.699 \\
\hline MMSE score, mean (SD) & $24.32(2.69)$ & $16.71(3.87)$ & $<0.001$ & $22.50(3.20)$ & $13.85(3.27)$ & $<0.001$ \\
\hline
\end{tabular}

SD standard deviation; MMSE Mini-Mental state examination; $C I$ cognitive impairment; WC waist circumstance; SBP systolic blood pressure; DBP diastolic blood pressure; $F B G$ fasting blood glucose; $T C$ total cholesterol; TG triglycerides; $H D L$ high-density lipoprotein cholesterol; $L D L$ low-density lipoprotein cholesterol

community in China [14]. In the present study, body height had a positive association with cognitive function among low-income elderly men in rural China; however, no relationship was found for elderly women. Furthermore, another longitudinal Chinese study found that arm length was associated with cognitive impairment in men during a 3-year follow-up, but not in women [23].

Adult body height is the result of a combination of genetic and environmental factors [6]. Childhood environment, including nutrition and disease, accounts for $20 \%$ of variation in body height. Thus, body height is a good indicator of childhood living conditions. Early deficiencies in nutrition in childhood have adverse effects on physical growth and brain development, which in turn affect cognitive development [24]. Our findings suggest that shorter height and early-life nutritional deprivation may contribute to cognitive impairment among elderly men. A structural magnetic resonance imaging analysis performed in 515 middle-aged male twins revealed the mechanisms underlying this relationship: height was positively associated with total cortical surface area among male twins, which underlies the phenotypic height and general cognitive ability relationship [25]. Besides, male fetuses are more sensitive to disadvantageous prenatal 
Table 3 Association of cognitive impairment with body height by sex and age, according to demographic characteristics and risk factor groups in the multivariate analysis

\begin{tabular}{lllr}
\hline Body height & $\begin{array}{l}\text { Model 1 } \\
\text { OR }(\mathbf{9 5 \%} \text { Cl) }\end{array}$ & $\begin{array}{l}\text { Model 2 } \\
\text { OR (95\% Cl) }\end{array}$ & $\begin{array}{c}\text { Model 3 } \\
\text { OR (95\% Cl) }\end{array}$ \\
\hline Male & $0.61(0.42,0.90)^{*}$ & $0.61(0.41,0.90)^{*}$ & $0.63(0.43,0.94)^{*}$ \\
60-64 years & $0.34(0.17,0.69)^{*}$ & $0.34(0.17,0.71)^{*}$ & $0.33(0.16,0.69)^{*}$ \\
65-69 years & $1.14(0.53,2.42)$ & $1.12(0.53,2.39)$ & $1.24(0.57,2.69)$ \\
$\geq 70$ years & $0.69(0.36,1.30)$ & $0.69(0.36,1.30)$ & $0.74(0.39,1.43)$ \\
Female & $1.07(0.77,1.49)$ & $1.07(0.77,1.49)$ & $1.08(0.77,1.50)$ \\
60-64 years & $0.91(0.52,1.59)$ & $0.91(0.52,1.59)$ & $0.88(0.50,1.54)$ \\
65-69 years & $0.87(0.45,1.70)$ & $0.93(0.47,1.83)$ & $0.93(0.47,1.85)$ \\
$\geq 70$ years & $1.33(0.78,2.28)$ & $1.28(0.74,2.20)$ & $1.54(0.86,2.75)$ \\
\hline
\end{tabular}

Model 1 analysis adjusted by age group and education group;

Model 2 analysis adjusted by age group, education group, smoking and drinking;

Model 3 analysis adjusted age, education, smoking, drinking, hypertension, diabetes and hypercholesterolemia

$* P \leq 0.05$

conditions compared with girls in previous studies, which lead to lower birth weights and early life illness among men [26, 27]. Therefore, height might be a better indicator of early life conditions for men than women. Thus, there is still a need to elucidate the sex difference between body height and cognitive impairment.

Cardiovascular variables, including hypertension, diabetes, hyperlipidemia, and smoking, are risk factors for cognitive decline, while education is an independent protective factor against cognitive impairment and dementia in later life [28-30]. In a population-based study in a rural region of South Africa, short height in old age was associated with poor cognitive decline among those without a formal education but not among those with at least 8 years of formal education [31]. However, in the present study, we failed to find mediating effects of education on the height and general cognitive ability relationship. Consistent with our findings, height was significantly associated with cognitive function independent of education and other covariates in an English longitudinal survey of aging [32].

There are several limitations in this study. First, the study population was from a low-income, low-education, rural population in northern China, so its representation and generalizability are limited. Second, cognitive impairment was evaluated with MMSE scores; therefore, different types of cognitive impairment could not be further diagnosed in the study. Third, other confounding factors, including APOE4 genotype and diet, are important factors for cognitive decline, but they were not assessed in this study. Forth, low birth weight could be an important factor on cognitive and socioeconomic outcomes [33]. As all participants did not experience malnutrition at time of maternal pregnancy or the first years of life, birth weight or history of drought or famine was not included in present study. Finally, this was a cross-sectional study, so causal relationships between cognitive function and height could not be determined.

\section{Conclusion}

In conclusion, shorter body height was associated with cognitive impairment independently of age, education, lifestyle factors, and health-related comorbid factors among low-income elderly men in rural China. The results suggest that childhood nutritional deprivation may contribute to cognitive impairment in later life. Accordingly, shorter elderly men may be targeted for effective dementia prevention in rural China. However, longitudinal cohort studies are warranted to confirm causality.

\section{Perspectives and significance section}

It is crucial to focus on the status of nutrition among adolescent males for preventing against the cognitive impairment at adult stage, especially among low-income population.

\section{Abbreviations \\ MMSE: Mini Mental State Examination; WC: Waist circumference; BP: Blood pressure; FBG: Fasting blood glucose; TC: Total cholesterol; TG: Triglycerides; HDL-C: High-density lipoprotein cholesterol; LDL-C: Low-density lipoprotein cholesterol; SBP: Systolic blood pressure; DBP: Diastolic blood pressure; ORs: Odds ratios; Cls: Confidence intervals.}

\section{Acknowledgements}

We thank all participants of the Tianjin Brain Study and the local medical care professionals for their valuable contributions.

\section{Authors' contributions}

$\mathrm{YWu}, \mathrm{XN}$, and JW participated in the design of the study and critical reviewed this manuscript. XN and JW participated in the design of the study and conceived of the study. JW performed the statistical analysis. DQ, CS, and RM participated to draft the manuscript. DQ, CS, RM, XY, JS, YWang, and JT 
participated in the data collection of this study. All authors read and approved the final manuscript.

\section{Funding}

Not applicable.

\section{Availability of data and materials}

Please contact author for data requests.

\section{Declarations}

\section{Ethics approval and consent to participate}

The study was approved by the ethics committee of Tianjin Medical University General Hospital and conformed to the Declaration of Helsinki regarding the use of human subjects. A written informed consent was obtained from each patient during recruitment.

\section{Consent for publication}

Not applicable.

\section{Competing interests}

The authors declare that they have no competing interests.

\section{Author details}

${ }^{1}$ Department of Neurology, Yiwu Central Hospital \& The Affiliated Yiwu Hospital of Wenzhou Medical College, 699 Jiangdong Road, Yiwu City 322000, Zhejiang, China. ${ }^{2}$ Department of Emergency Medicine, Yiwu Central Hospital \&The Affiliated Yiwu Hospital of Wenzhou Medical College, 699 Jiangdong Road, Yiwu City 322000, Zhejiang, China. ${ }^{3}$ Department of Neurology, Tianjin Medical University General Hospital, 154 Anshan Road, Heping District, Tianjin 300052, China. ${ }^{4}$ Laboratory of Epidemiology, Tianjin Neurological Institute, 154 Anshan Road, Heping District, Tianjin 300052, China. ${ }^{5}$ Tianjin Neurological Institute, Key Laboratory of Post-Neuroinjury Neuro-Repair and Regeneration in Central Nervous System, Ministry of Education and Tianjin City, 154 Anshan Road, Heping District, Tianjin 300052, China.

\section{Received: 26 April 2021 Accepted: 10 November 2021}

Published online: 06 December 2021

\section{References}

1. GBD 2017 DALYs and HALE Collaborators. Global, regional, and national disability-adjusted life-years (DALYs) for 359 diseases and injuries and healthy life expectancy (HALE) for 195 countries and territories, 19902017: a systematic analysis for the Global Burden of Disease Study 2017. Lancet. 2018;392:1859-922.

2. Wortmann M. Dementia: a global health priority - highlights from an ADI and World Health Organization report. Alzheimers Res Ther. 2012;4:40.

3. Wimo A, Jönsson L, Bond J, Prince M, Winblad B. Alzheimer Disease International. The worldwide economic impact of dementia 2010. Alzheimers Dement. 2013;9:1-11

4. Ferri $C P$, Prince $M$, Brayne C, Brodaty $H$, Fratiglioni L, Ganguli M, et al. Global prevalence of dementia: a Delphi consensus study. Lancet. 2005:366:2112-7.

5. Jia L, Quan M, Fu Y, Zhao T, Li Y, Wei C, et al. Dementia in China: epidemiology, clinical management, and research advances. Lancet Neurol. 2020;19:81-92.

6. Silventoinen K. Determinants of variation in adult body height. J Biosoc Sci. 2003;35:263-85.

7. Abbott RD, White LR, Ross GW, Petrovitch H, Masaki KH, Snowdon DA, et al. Height as a marker of childhood development and late-life cognitive function: the Honolulu-Asia Aging Study. Pediatrics. 1998;102:602-9.

8. Guven C, Lee WS. Height, aging and cognitive abilities across Europe. Econ Hum Biol. 2015;16:16-29.

9. Pereira VH, Costa PS, Santos NC, Pedro GC, Margarida CN, Joana AP, et al. Adult body height is a good predictor of different dimensions of cognitive function in aged individuals: a cross-sectional study. Front Aging Neurosci. 2016;8:217.
10. West RK, Ravona-Springer R, Heymann A, Schmeidler J, Leroith D, Koifman K, et al. Shorter adult height is associated with poorer cognitive performance in elderly men with type II diabetes. J Alzheimers Dis. 2015;44:927-35.

11. Jørgensen T, Okholm GT, Christensen K, Sørensen TI, Osler M. Body height in young adult men and risk of dementia later in adult life. Elife. 2020;9:e51168.

12. Laitala VS, Hjelmborg J, Koskenvuo M, Räihä I, Rinne JO, Christensen K, et al. Shorter adult stature increases the impact of risk factors for cognitive impairment: a comparison of two Nordic twin cohorts. Twin Res Hum Genet. 2011;14:544-52.

13. Heys M, Schooling CM, Jiang C, Adab P, Cheng KK, Lam TH, et al. Childhood growth and adulthood cognition in a rapidly developing population. Epidemiology. 2009;20:91-9.

14. Liang X, Li X, Ding D, Zhao Q, Luo J, Guo Q, et al. Short sitting height and low relative sitting height are associated with severe cognitive impairment among older women in an urban community in China. Neuroepidemiology. 2015;45:257-63.

15. Wang J, Ning X, Yang L, Tu J, Gu H, Zhan C, et al. Sex differences in trends of incidence and mortality of first-ever stroke in rural Tianjin, China, from 1992 to 2012. Stroke. 2014;45:1626-31.

16. Wang J, An Z, Li B, Yang L, Tu J, Gu H, et al. Increasing stroke incidence and prevalence of risk factors in a low-income Chinese population. Neurology. 2015;84:374-81.

17. Canadian Task Force on Preventive Health Care, Pottie K, Rahal R, Jaramillo A, Birtwhistle R, Thombs BD, et al. Recommendations on screening for cognitive impairment in older adults. CMAJ. 2016;188:37-46.

18. Nunes B, Silva RD, Cruz VT, Roriz JM, Pais J, Silva MC. Prevalence and pattern of cognitive impairment in rural and urban populations from Northern Portugal. BMC Neurol. 2010;10:42.

19. Tisserand DJ, Bosma H, Van Boxtel MP, Jolles J. Head size and cognitive ability in nondemented older adults are related. Neurology. 2001;56:969-71.

20. Perneczky R, Wagenpfeil S, Lunetta KL, Cupples LA, Green RC, Decarli C, et al. Head circumference, atrophy, and cognition: implications for brain reserve in Alzheimer disease. Neurology. 2010;75:137-42

21. Ahmed A, Kramer MS, Bernard JY, Trejo MEP, Martin RM, Oken E, et al. Early-childhood-growth trajectory and later cognitive ability: evidence from a large prospective birth cohort of healthy term-born children. Int J Epidemiol. 2021;49:1998-2009.

22. Quan SA, Jeong JY, Kim DH. The relationship between height and cognitive function among community-dwelling elderly: Hallym Aging Study. Epidemiol Health. 2013;35:e2013002.

23. Zhang Z, Gu D, Hayward MD. Childhood nutritional deprivation and cognitive impairment among older Chinese people. Soc Sci Med. 2010;71:941-9.

24. Jukes $M$. The long-term impact of preschool health and nutrition on education. Food Nutr Bull. 2005;26:S193-201.

25. Vuoksimaa E, Panizzon MS, Franz CE, et al. Brain structure mediates the association between height and cognitive ability. Brain Struct Funct. 2018;223:3487-94.

26. Verloove-Vanhorick SP, van Zeben-van der Aa DM, Verwey RA, Brand R, Ruys JH. The male disadvantage in very low birthweight infants: does it really exist. Eur J Pediatr. 1989;149:197-202.

27. Kirchengast $\mathrm{H}$. The male disadvantage hypothesis reconsidered: is there really a weaker sex? An analysis of gender differences in newborn somatometrics and vital parameters. J Life Sci. 2009;1:63-71.

28. Nguyen TT, Tchetgen Tchetgen EJ, Kawachi I, et al. Instrumental variable approaches to identifying the causal effect of educational attainment on dementia risk. Ann Epidemiol. 2016;26:71-6.

29. Clouston SA, Kuh D, Herd P, Elliott J, Richards M, Hofer SM. Benefits of educational attainment on adult fluid cognition: international evidence from three birth cohorts. Int J Epidemiol. 2012;41:1729-36.

30. Kivipelto M, Mangialasche F, Ngandu T. Lifestyle interventions to prevent cognitive impairment, dementia and Alzheimer disease. Nat Rev Neurol. 2018;14:653-66.

31. Kobayashi LC, Berkman LF, Wagner RG, Kahn K, Tollman S, Subramanian SV. Education modifies the relationship between height and cognitive function in a cross-sectional population-based study of older adults in Rural South Africa. Eur J Epidemiol. 2019;34:131-9. 
32. Guven C, Lee WS. Height and cognitive function at older ages: is height a useful summary measure of early childhood experiences. Health Econ. 2013;22:224-33.

33. Orri M, Pingault JB, Turecki G, Nuyt AM, Geoffroy MC. Contribution of birth weight to mental health, cognitive and socioeconomic outcomes: twosample mendelian randomisation. Br J Psychiat. 2021;7:1-8.

\section{Publisher's Note}

Springer Nature remains neutral with regard to jurisdictional claims in published maps and institutional affiliations.

- fast, convenient online submission

- thorough peer review by experienced researchers in your field

- rapid publication on acceptance

- support for research data, including large and complex data types

- gold Open Access which fosters wider collaboration and increased citations

- maximum visibility for your research: over $100 \mathrm{M}$ website views per year

At BMC, research is always in progress.

Learn more biomedcentral.com/submissions 